\title{
Retransplantation improves survival in pediatric lung transplant recipients
}

\author{
Michael Hsin, MD, FRCS CTh (Eng), ${ }^{a}$ and Marcelo Cypel, MD, MSc, FRCSC ${ }^{b}$
}

\author{
From the a Department of Cardiothoracic Surgery, Queen Mary Hospital, Hong Kong, China; and ${ }^{\mathrm{b}}$ Division of \\ Thoracic Surgery, University of Toronto, Toronto, Ontario, Canada. \\ Disclosures: Authors have nothing to disclose with regard to commercial support. \\ Received for publication Aug 9, 2018; accepted for publication Aug 10, 2018. \\ Address for reprints: Michael Hsin, MD, FRCS CTh (Eng), Queen Mary Hospital, Cardiothoracic Surgery, 102 \\ Pok Fu Lam Rd, High West, Hong Kong SAR, China (E-mail: mkhsin@hotmail.com). \\ J Thorac Cardiovasc Surg 2018;156:2037-8 \\ $0022-5223 / \$ 36.00$ \\ Copyright (C) 2018 by The American Association for Thoracic Surgery \\ https://doi.org/10.1016/j.jtcvs.2018.08.030
}

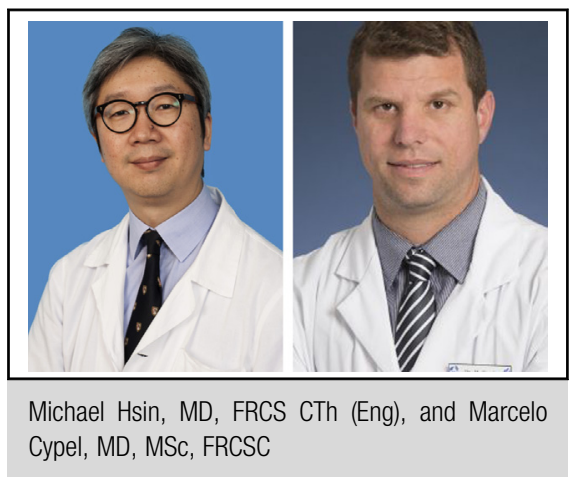

Central Message

Chronic lung allograft dysfunction remains a formidable challenge in pediatric lung transplant recipients, but the Vienna group's policy of retransplantation has resulted in improved overall survival.

See Article page 2025. center experience published to date on pediatric lung transplant.

Waseda and colleagues ${ }^{1}$ divided their series into an early era (1990-2003) and a recent era (2003-2015). For the recent era, the 5-year survival was $73.9 \%$, which compares very favorably with the International Society for Heart and Lung Transplantation registry pediatric data $(56.4 \%$ for the period of 2008-2013). ${ }^{2}$ Indeed, the International Society for Heart and Lung Transplantation 5-year survival for adult transplant for the same era was $55.4 \%$; in Vienna, it was $71.2 \%$.

Several features of the experience reported by Waseda and colleagues ${ }^{1}$ deserve discussion. In the more recent era, similar to their adult transplant practice, intraoperative extracorporeal membrane oxygenation (ECMO) was used liberally (close to $90 \%$ ). In fact, this same group recently demonstrated significantly improved short- and long-term outcomes by routinely using ECMO during transplant operations. ${ }^{3}$ Furthermore, they electively extended ECMO support into the postoperative period in $33 \%$ of cases. This decision was based on the donor organ quality, the intraoperative assessment, and the recipient risk profile. The true rate of primary graft dysfunction was therefore unclear, but it is possible that a significant number of these patients receiving "elective" ECMO support would otherwise have had high-grade primary graft dysfunction develop.

Size-reduction procedures were common, and lobar transplant was used in more than one-third of recipients in the recent era. Induction therapy with alemtuzumab was used in $76 \%$ of patients in the recent era.

the Vienna group's retrospective, single-center experience of pediatric lung transplantation from 1990 to 2015 , composed of 86 transplants, $97.7 \%$ of which were bilateral lung transplants. In the final 5 years of the series, their annual case load was between 5 to 9 transplants, qualifying them as a high-volume center. This is also the largest single-

.

.
outcomes in the United Network for Organ Sharing database (survival and graft half-live) improved in the later era (2002-2008) compared with the earlier eras (19881994, 1995-2001). This was entirely driven, however, by improvement in 1-year survival in the more recent era. Conditional 1-year survival was not different among the 3 periods. Zafar and associates ${ }^{4}$ concluded that chronic rejection continued to have a negative effect on late graft survival, with little improvement in effective therapies.

What does the Vienna experience show? In their recent era, the overall survival on conditional 1-year survival was superior to that in the early era, meaning the improvement in overall survival came not just because of improvement in perioperative measures but also because of the long-term management. Organ survival, however, was not significantly different between the first and second eras. In the recent era, 10-year organ survival was $52.1 \%$, whereas the 10 -year overall survival was $73.9 \%$. Waseda and associates ${ }^{1}$ attribute this to their policy of elective retransplantation for patients who survive beyond 1 year after the primary lung transplant (12 patients in this series).

The Vienna experience underscores that chronic lung allograft dysfunction remains a major challenge. Although retransplantation appears to be the solution, clearly more 
work is needed in the prevention, early identification, and treatment of chronic lung allograft dysfunction, so that improved long-term outcomes can be achieved.

\section{References}

1. Waseda R, Benazzo A, Hoetzenecker K, Jaksch P, Muraközy G, Gruber S, et al. The influence of retransplantation on survival for pediatric lung transplant recipients. J Thorac Cardiovasc Surg. 2018;156:2025-34.e2.

2. Goldfarb SB, Benden C, Edwards LB, Kucheryavaya AY, Dipchand AI, Levvey BJ, et al. The registry of the International Society for Heart and Lung
Transplantation: eighteenth official pediatric lung and heart-lung transplantation report-2015; focus theme: early graft failure. J Heart Lung Transplant. 2015; 34:1255-63.

3. Hoetzenecker K, Schwarz S, Muckenhuber M, Benazzo A, Frommlet F, Schweiger $\mathrm{T}$, et al. Intraoperative extracorporeal membrane oxygenation and the possibility of postoperative prolongation improve survival in bilateral lung transplantation. J Thorac Cardiovasc Surg. 2018;155: 2193-206.e3.

4. Zafar F, Heinle JS, Schecter MG, Rossano JW, Mallory GB Jr, Elidemir O, et al. Two decades of pediatric lung transplant in the United States: have we improved? J Thorac Cardiovasc Surg. 2011;141:828-32.e1. 